\title{
Resultados paleomagnéticos preliminares do Complexo máfico-ultramáfico Rincón del Tigre - Leste da Bolívia, Cráton Amazônico.
}

\author{
Oscar A. L. Patroni ${ }^{1}$, Manoel S. D’Agrella-Filho ${ }^{1}$, Ramiro Matos ${ }^{2}$, Amarildo S. Ruiz ${ }^{3}$ \\ ${ }^{1}$ Universidade de São Paulo, ${ }^{2}$ Universidad Mayor de San Andrés; ${ }^{3}$ Universidade Federal de Mato Grosso
}

Copyright 2014, SBGf - Sociedade Brasileira de Geofísica

Este texto foi preparado para a apresentação no VI Simpósio Brasileiro de Geofísica, Porto Alegre, 14 a 16 de outubro de 2014. Seu conteúdo foi revisado pelo Comitê Técnico do VI SimBGf, mas não necessariamente representa a opinião da SBGf ou de seus associados. É proibida a reprodução total ou parcial deste material para propósitos comerciais sem prévia autorização da SBG.

\section{Resumo}

Este trabalho apresenta dados paleomagnéticos preliminares obtidos para rochas intrusivas datadas em $1.110,4 \pm 1,8 \mathrm{Ma}(\mathrm{U}-\mathrm{Pb}$ em badeleíta) pertencentes ao Complexo máfico-ultramáfico Rincón del Tigre, localizado na região leste da Bolívia. Para o estudo, 101 amostras cilíndricas orientadas da composição mais máfica do complexo foram coletadas de 15 sítios. No laboratório, um total de 359 espécimes cilíndricos de $2,5 \mathrm{~cm}$ de altura por $2,5 \mathrm{~cm}$ de diâmetro foram preparados para os tratamentos por campos magnéticos alternados (AF) e térmicos, assim como, para as medidas de anisotropia de suscetibilidade magnética (ASM). Os resultados de ASM indicam, para a maioria das amostras analisadas, dois tipos de tramas magnéticas: trama planar coerente com a colocação de sills, com lineação magnética para NW/SE e trama com foliação magnética definida pelos eixos K1 e K2 também de direção NW/SE. Ambas as tramas são coerentes com a direção do cinturão Sunsás. Através de desmagnetizações sucessivas por meio da aplicação de campos magnéticos alternados, tem sido possível isolar direções oeste (leste) com inclinações baixas (de ambas as polaridades) para a maioria das amostras investigadas. Estes dados preliminares, quando comparados com outros disponíveis na literatura, têm implicações tectônicas importantes quanto à interação entre o Cráton Amazônico e a Laurentia na formação do supercontinente Rodinia há 1.110 Ma atrás.

\section{Introdução}

As reconstruções paleogeográficas são essenciais para a compreensão do ciclo continental no passado geológico. O Cráton Amazônico representa uma das maiores áreas cratônicas do Planeta e teve participação importante na formação do supercontinente Meso-Neoproterozoico Rodinia. Segundo modelos geológicos, durante a formação do Rodinia, o Cráton Amazônico colidiu com a Laurentia ao longo dos cinturões Sunsás e Grenville, respectivamente. Basicamente, dois modelos de colisão distintos têm sido propostos (Evans, 2013): o primeiro sugere uma colisão obliqua do Cráton Amazônico ao longo do cinturão Lhano (no Texas), há $1.200 \mathrm{Ma}$ atrás, seguido de movimento transcorrente até a sua posição final na região do Labrador, há cerca de 1.070-1.000 Ma, quando colide com o continente Báltico (Tohver et al., 2004, Ibanez-Mejia et al., 2011). Um segundo modelo propõe uma colisão frontal do
Cráton Amazônico ao longo do cinturão Grenville (região do Labrador) (Li et al., 2008, Evans, 2013). Segundo este modelo, após a ruptura do núcleo do supercontinente Columbia (formado por Laurentia, Báltica, Cráton Amazônico/Oeste-África) há aproximadamente 1.270 Ma, o bloco Amazônia/Oeste África executou movimento de rotação no sentido horário até o choque final com a Laurentia, há cerca de 1.000 Ma. Deste modo, a obtenção de polos paleomagnéticos bem datados para o Cráton Amazônico para o intervalo entre 1.200 e $1.000 \mathrm{Ma}$ torna-se crucial para definir qual foi a cinemática desta unidade cratônica durante esta época importante da história da Terra. Rochas máficas e ultramáficas aflorantes no leste-sudeste da Bolívia (parte ocidental/meridional do Cráton Amazônico), formam o Complexo Ígneo Rincón del Tigre. Estas rochas foram recentemente datadas pelo método $\mathrm{U}-\mathrm{Pb}$ (Badeleita) em 1.110,4 $\pm 1,8 \mathrm{Ma}$ (Teixeira et al., 2014) o que as tornam um alvo importante para 0 estudo paleomagnético visando a elucidação da evolução geodinâmica deste cráton na formação do supercontinente Rodinia.

\section{Contexto geológico e metodologia}

O complexo Rincón del Tigre é formado por rochas máficas-ultramáficas intrusivas, dispostas em sills acamadados, com uma espessura de aproximadamente $4,5 \mathrm{~km}$ (Teixeira et al., 2014). Apresenta relações intrusivas com rochas sedimentares pertencentes aos Grupos Sunsás e Vibosi, as quais fazem parte do cinturão Sunsás, caracterizado por um cinturão colisional de direção NW/SE ( 1.200-1.000 Ma). O complexo Rincón del Tigre é composto por rochas ultrabásicas (dunitos serpentinizados, harzburgitos, bronzonito olivina, picrito bronzonito), além de rochas máficas (noritos e gabros) e, adicionalmente, por granófiros. Para o trabalho paleomagnético, foram amostrados 101 testemunhos cilíndricos orientados (através de bússolas solar e magnética) da composição mais máfica do complexo, pertencentes a 15 sítios. No laboratório, um total de 359 espécimes cilíndricos de $2,5 \mathrm{~cm}$ de altura por 2,5 $\mathrm{cm}$ de diâmetro foram preparados para os tratamentos por campos magnéticos alternados $(\mathrm{AF})$ e térmicos, assim como, para as medidas de anisotropia de suscetibilidade magnética (ASM). Para o tratamento AF foi aplicada a seguinte sequência de campos alternados: $2,5,5,7,5,10,12,515,20,25,30,35,40$, $45,50,55,60,70,80,90$ e $100 \mathrm{mT}$, utilizando um desmagnetizador AF rotativo da marca MOLSPIN. Utilizou-se um magnetômetro JR6-A (AGICO) para as medidas da magnetização. Para a análise das direções, foram utilizadas projeções estereográficas e ortogonais e o método de componentes principais de Kirschvink (1980) para a determinação das 
componentes de magnetização. As medidas de ASM em baixo campo foram efetuadas para determinar a trama magnética das rochas utilizando um aparelho Kappabridge KLY-4S (AGICO). Os autovetores das médias das ASMs (suscetibilidades máxima, K1, intermediária, K2, e mínima, K3) foram calculados usando o método bootstrap de Constable \& Tauxe (1990).

\section{Resultados}

As medidas de ASM indicam dois intervalos de suscetibilidades magnéticas médias $(\mathrm{Km})$ associadas às amostras analisadas (Figura 1a). $O$ primeiro apresenta valores entre $2,6 \times 10^{-4}$ e $220 \times 10^{-4}$ (SI) e o segundo, entre $250 \times 10^{-4}$ e $860 \times 10^{-4}$ (SI). As medidas indicam também graus de anisotropia $(P)$ desde valores compatíveis com rochas máficas intrusivas não deformadas $(<1,1)$ até valores bastante elevados com um máximo de 1,58 (Figura 1a), indicando que as amostras foram submetidas a algum tipo de deformação.

O parâmetro de Jelinek (T) índica um predomínio de elipsoides oblatos $(0<T<1)$ sugerindo também predominância de foliação magnética (Figura 1b).

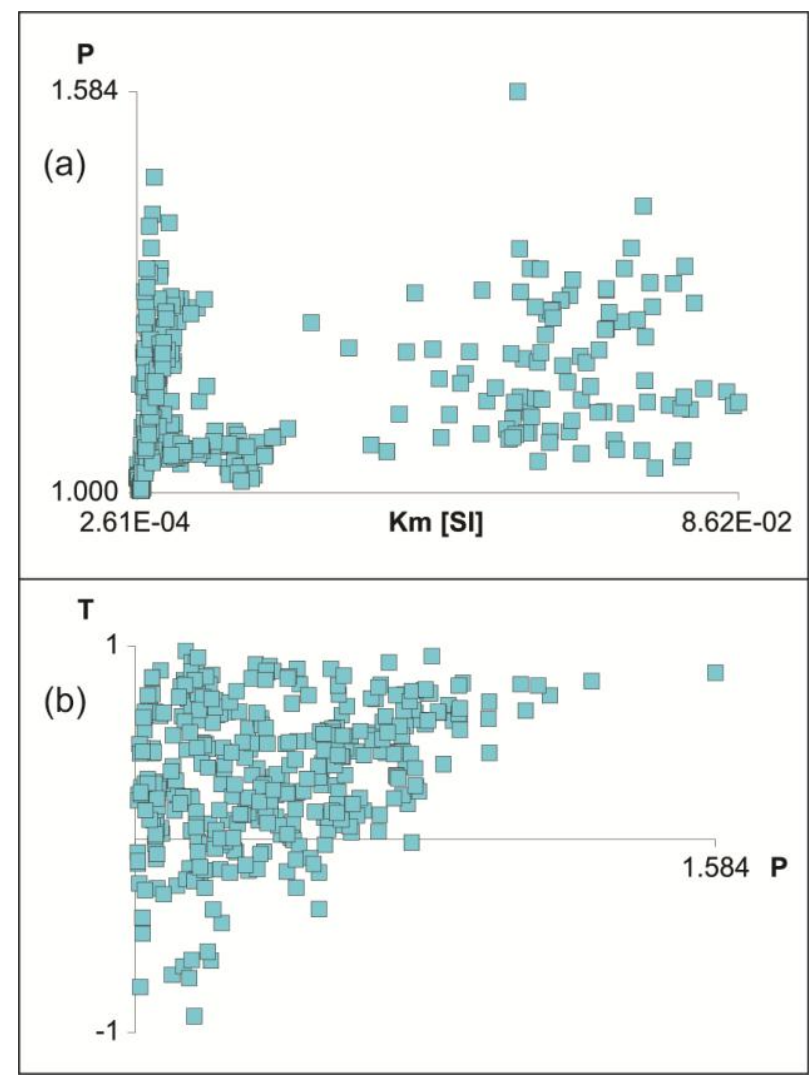

Figura 1 - (a) Grau de anisotropia $(P)$ versus suscetibilidade média $(\mathrm{Km})$ por amostra; (b) parâmetro de Jelinek $(T)$ versus grau de anisotropia ( $P$ por amostra).

Dois tipos de tramas magnéticas são predominantes nas amostras analisadas: a primeira é representada por trama planar (eixo K3 próximo do centro do estereograma da Figura 2a), com lineação magnética NW/SE definida pelo eixo K1. O segundo tipo de trama indica foliação magnética definida pelos eixos K1 e K2 na direção NW/SE e o eixo K3 perpendicular a este plano (Figura 2b).

O tratamento por campos magnéticos alternados revelaram componentes estáveis para a maioria das amostras analisadas. A intensidade da magnetização remanente natural (MRN) varia desde valores baixos $\left(2,4 \times 10^{-3} \mathrm{~A} / \mathrm{m}\right)$ até valores altos $(172 \mathrm{~A} / \mathrm{m})$, compatíveis com rochas máficas. Após a eliminação de componentes secundárias com coercividades baixas de até 20-30 mT, o tratamento por campos alternados tem revelado direções oeste (leste) com inclinações baixas (de ambas as polaridades) para boa parte das amostras analisadas (Figura 3).

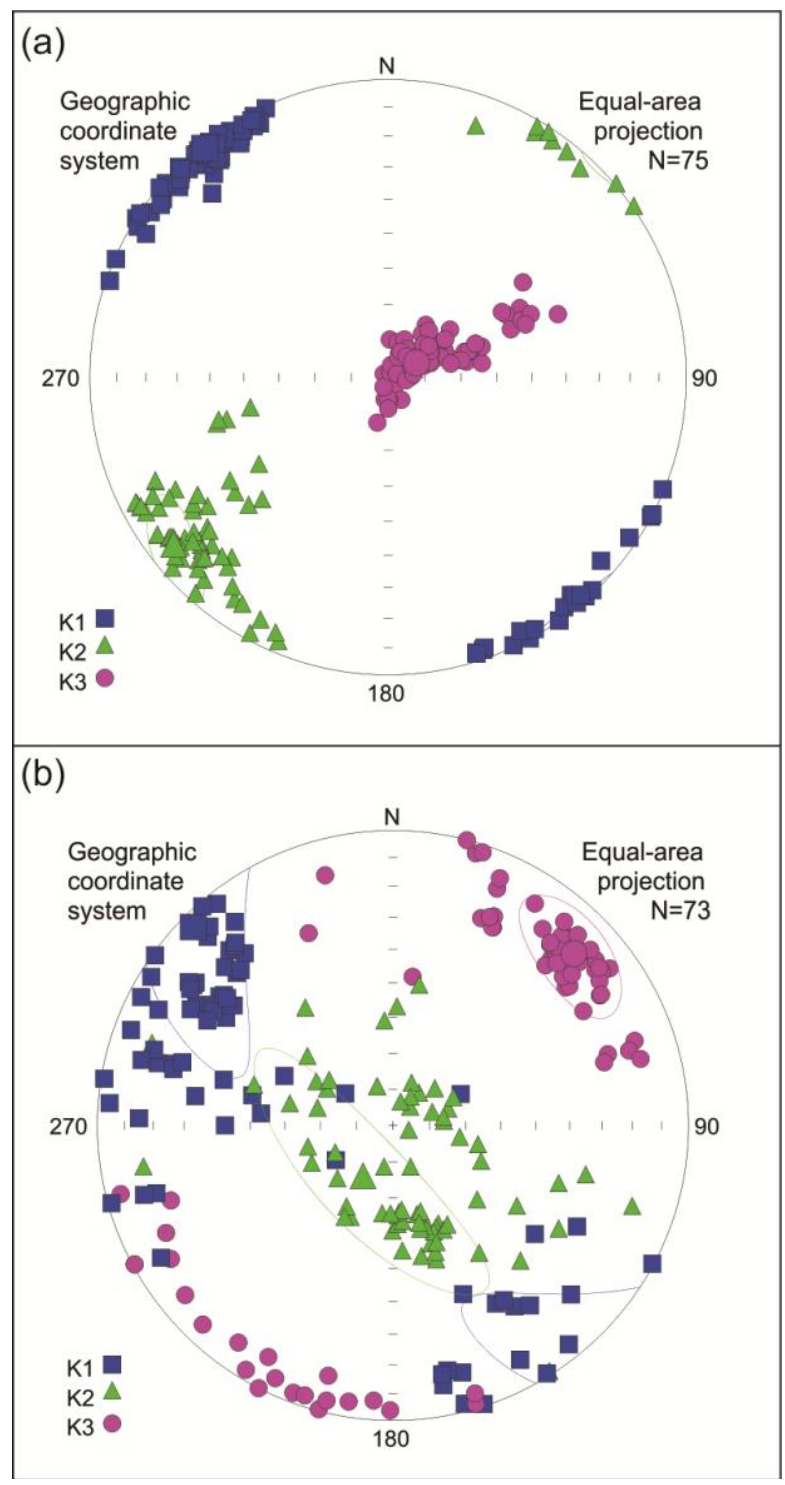

Figura 2 - Estereogramas mostrando exemplos representativos de direções dos eixos de suscetibilidade magnética (máxima (K1) intermediária (K2) e mínima (K3)) por amostra, os quais indicam a trama magnética obtidas para os sítios 2, 5 e 9 (a) e para os sítios 3, 4 e 14 (b). 


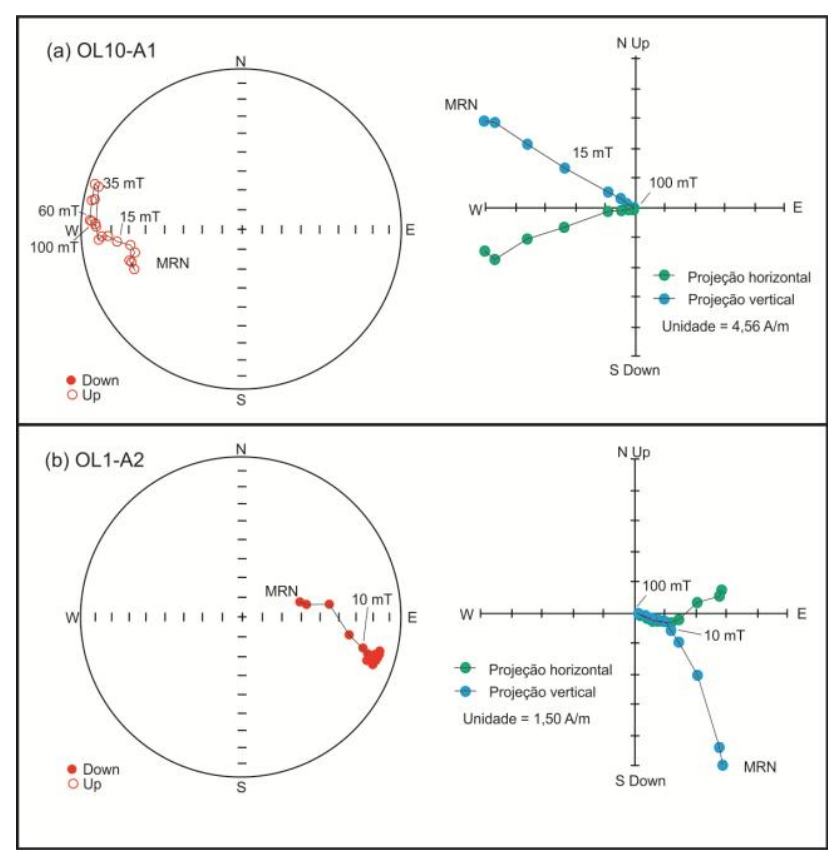

Figura 3 - Exemplos de desmagnetização por campos alternados: projeção estereográfica (lado esquerdo) e projeção ortogonal (lado direito). (a) direção oeste com inclinação negativa baixa; (b) direção leste/sudeste com inclinação positiva.

\section{Discussão e Conclusões}

Os resultados de ASM indicam, para parte das amostras analisadas, trama magnética planar coerente com a colocação de sills (Figura 2a). Para estas amostras, o eixo K1 agrupa-se na direção NW-SE o que indica que a colocação destas rochas pode ter sido influenciada pela estruturação tectônica do cinturão Sunsás, o qual apresenta a mesma direção NW/SE. Os dados indicam também um predomínio de elipsoides oblatos (parâmetro de Jelinek entre 0 e 1) e, em consequência, a dominância de foliação magnética em relação à lineação magnética. Uma foliação magnética NW/SE foi observada em parte das amostras analisadas (Figura 2b) o que pode indicar que estas amostras foram parcialmente deformadas pelo evento Sunsás.

Através de desmagnetizações sucessivas por meio da aplicação de campos magnéticos alternados, tem sido possível isolar direções oeste (leste) com inclinações baixas (de ambas as polaridades) para a maioria das amostras investigadas. Estes dados preliminares, quando comparados com outros disponíveis na literatura, têm implicações tectônicas importantes quanto à interação entre o Craton Amazônico e a Laurentia na formação do supercontinente Rodinia há 1.110 Ma atrás.

\section{Agradecimentos}

Agradecemos à Fundação de Amparo à Pesquisa do estado de São Paulo (processo FAPESP 2011/508876) e à CAPES pelo apoio financeiro.

\section{Referências}

Constable, C. \& Tauxe, L., 1990. The boostrap for magnetic susceptibility tensor. Journal of Geophysical Research, 95: 8383-8395.

Evans, D.A.D., 2013. Reconstructing pre-Pangean supercontinents. GSA Bulletim, 125 : 1735-1751

Ibanez-Mejia, M., Ruiz, J., Valencia, V.A., Cardona, A., Gehrels, G.E. \& Mora, A.R., 2011. The Putumayo Orogen of Amazonia and its implications for Rodinia reconstructions: New U-Pb geochronological insights into the Proterozoic tectonic evolution of northwestern South America. Precambrian Research, 191 : 58-77.

Li, Z.X., Bogdanova, S.V., Collins, A.S., Davidson, A., De Waele, B., Ernst, R.E., Fitzsimons, I.C.W., Fuck, R.A., Gladkochub, D.P., Jacobs, J., Karlstrom, K.E., Lu, S., Natapov, L.M., Pease, V., Pisarevsky, S.A., Thrane, K. \& Vernikovsky, V., 2008. Assembly, configuration, and break-up history of Rodinia: A synthesis. Precambrian Research, 160: 179-210.

Teixeira, W., Hamilton, M.A., Lima, G.A., Ruiz, A.S., Matos, R. \& Ernst, R.E., 2014. Precise ID-TIMS U-Pb baddeleyite ages (1110-1112 Ma) for the Rincón del Tigre-Huanchaca large igneous province (LIP) of the Amazonian Craton: implications for the Rodinia supercontinent. Precambrian Research, (no prelo).

Tohver, E., Bettencourt, J.S., Tosdal, R., Mezger, K., Leite, W.B. \& Payolla, B.L., 2004. Terrane transfer during the Grenville orogeny: tracing the Amazonian ancestry of southern Appalachian basement through $\mathrm{Pb}$ and Nd isotopes. Earth Planetary Science Letters, 228: 161-176. 